\title{
Entre la minimización y la expansión del Derecho Penal: la presencia de Beccaria en el debate contemporáneo*
}

\author{
Omar Huertas Díaz" \\ Manuel Alberto Leyva Estupiñán \\ Larisbel Lugo Arteaga \\ Milton Fabián Perdomo Mejía \\ Astelio Silvero Sarmiento
}

Recibido: 20 de enero de 2016 • Revisado: 7 de febrero de 2016

Aprobado: 22 de febrero de 2016

\begin{abstract}
"El presente artículo de investigación en trabajo colaborativo es resultado de los Grupos de Investigación Escuela de Derecho Penal "Nullum Crimen Sine Lege UN" Reconocido y Clasificado en D COLCIENCIAS 2014; Grupo de Investigación Bkria de la Universidad Autónoma de Colombia, Reconocido por COLCIENCIAS 2014; Grupo de Investigación de la Universidad de Holguin Cuba y Grupo de Investigación de la Corporación Universitaria Americana. El documento es producto del proyecto de investigación: El Recurso Extraordinario de Casación y la Acción de Revisión en el Sistema Penal Acusatorio. El citado proyecto de investigación es financiado por la Universidad Autónoma.

"* Abogado, Especialista en Derecho Penal, Profesor Asociado y Candidato a Doctor de la Universidad Nacional de Colombia; Máster en Derechos Humanos, Estado de Derecho y Democracia en Iberoamérica de la Universidad de Alcalá (España); Magíster en Derecho Penal, de la Universidad Libre; Magíster en Educación, de la Universidad Pedagógica Nacional. Par Académico Ministerio de Educación Nacional. Correo electrónico: ohuertasd@unal.edu.co.

*as Profesor Auxiliar de Derecho Penal en la Universidad de Holguín, Cuba. Licenciado en Derecho en el 2005 por la Universidad de Camagüey, Cuba. Especialista en Derecho Penal por la Universidad de Holguín. Actualmente cursa el doctorado en Ciencias Jurídicas por la Facultad de Derecho de la Universidad de Oriente, Cuba. Profesor en la República Bolivariana de Venezuela durante los años 2008 y 2009. Miembro de la Sociedad Cubana de Ciencias Penales en su capítulo de la provincia Holguín. Correo electrónico: mleyva@fh.uho.edu.cu.

${ }^{*+*}$ Profesora Asistente de Derecho Penal Especial en la Universidad de Holguín, Cuba. Licenciada en Derecho en el 2005 por la Universidad de Camagüey, Cuba. Se desempeñó como jueza en el Tribunal Provincial Popular de Camagüey en su Sala Quinta de lo Penal. Especialista en Derecho Penal por la Universidad de Holguín. Miembro de la Sociedad Cubana de Ciencias Penales en su capítulo de la provincia Holguín. Correo electrónico: 1lugo@fh.uho.edu.cu.

Abogado de la Universidad Autónoma de Colombia, Especialista en Derecho Penal, Magíster en Derecho, profundización en Sociología y Política Criminal y profesor de Cátedra Universidad Nacional de Colombia; Profesor Universidad Republicana; Investigador del grupo "Bkria" de la Universidad Autónoma de Colombia. Correo electrónico: mfperdomom@unal.edu.co.

Abogado - Universidad del Atlántico. Docente investigador (JR) Corporación Universitaria Americana, Magister en Educación Universidad del Atlántico - SUE Caribe (Barranquilla). Doctorando en Ciencias de la Educación Universidad Simón Bolívar (Barranquilla).Correo electrónico: genionet@ hotmail.com.
\end{abstract}




\title{
Resumen
}

En el Derecho penal contemporáneo se producen las mismas discusiones que se manifestaron hace más de doscientos años. ¿Qué fines persigue la pena?, ¿qué debemos proteger a través del Derecho penal y qué debe ser tutelado por otras formas menos violentas?, ¿¿uál es el fin del Derecho penal? Éstas y algunos otros interrogantes son los que han matizado durante décadas el tema del delito y el delincuente en un Estado de Derecho. En la actual sociedad del riesgo, se está produciendo una expansión del sentido y alcance del Derecho penal. Esta expansión socava las bases de la pretensión de un Derecho penal de última ratio, más cuando el nuevo modelo de Estado ha superado el Estado de Derecho, transformándose en un Estado Social y Democrático de Derecho. Algunas de las claves conceptuales para el logro de este derecho penal mínimo pueden ser encontradas en la obra de Beccaria hace ya más de doscientos años.

Palabras clave: Beccaria, Derecho Penal, sanción, principios, sistema de enjuiciamiento.

\section{Between the minimization and expansion of Criminal LAW: THE PRESENCE OF BECCARIA IN THE CONTEMPORARY DEBATE}

\begin{abstract}
In the contemporary criminal law the same arguments that were manifested over two hundred years ago produced. What ends worth pursuing ? What should we protect through criminal law and what should be protected by other less violent ways? What is the purpose of criminal law ? These and some other questions are the ones who for decades have clarified the issue of crime and the offender in the rule of law . In today's society of risk it is occurring expansion of the meaning and scope of criminal law. This expansion undermines the foundations of the criminal law claim of last resort, especially when the new model of State has exceeded the rule of law , becoming a social and democratic state of law. Some of the key concepts to achieve this minimum criminal law can be found in the work of Beccaria over two hundred years ago.
\end{abstract}

Keywords: Beccaria, Criminal Law, sanction, principles, system of judging. 


\section{Entre a minimização e a expansão do Direito Penal: a PRESENÇA DE BECCARIA NO DEBATE CONTEMPORÂNEO}

\section{Resumo}

No Direito penal contemporâneo produzem-se as mesmas discussões que foram manifestas a mais de duzentos anos atrás. O que fins a que prossegue a sentença?, O que devemos proteger através do Direito penal e o que deve ser tutelado por outras formas menos violentas?, Qual é a finalidade do Direito penal? Estas e algumas outras questões são aquelas que têm matizado durante décadas a questão do crime e o infrator em um Estado de Direito. Na sociedade de hoje de risco, está-se produzindo uma expansão do sentido e alcance do Direito penal. Esta expansão corroem as bases da pretensão de um Direito penal atual, especialmente quando o novo modelo de Estado excedeu o Estado de Direito, tornando-se num Estado Social e Democrático de Direito. Alguns dos conceitos-chave para o sucesso esse direito penal mínimo podem ser encontradas na obra de Beccaria a qual tem mais de duzentos anos.

Palavras-chave: Beccaria, Direito Penal, punição, princípios, sistema e julgamento.

\section{Introducción}

Hoy como ayer, modelos contrapuestos en el Derecho penal se discuten ante la aparición de viejos y nuevos riesgos para la sociedad. La aspiración de un modelo de Derecho penal mínimo sigue asentada en la aquella tradición iluminista occidental, la cual tiene entre sus fundamentos, la existencia de un mínimo de figuras delictivas en la legislación penal, aquellos actos que agravien más al ser humano, el rechazo a la pena de muerte como sanción penal, y la búsqueda de alternativas al recurrente uso de la acción penal. Contrario a esa pretensión minimalista propia del desarrollo del principio de última ratio emerge un Derecho penal expansivo, que lejos de prohibir y sancionar únicamente aquellas conductas lesivas de bienes jurídicos fundamentales, incorpora nuevas figuras delictivas, que supone un adelantamiento de la justicia penal y la negación de garantías fundamentales. Algunos de los argumentos para este Derecho penal de prima ratio se localizan en el auge del terrorismo, la aparición de nuevas formas de criminalidad organizada y, en sentido general, la sensación de inseguridad ciudadana ante los nuevos riesgos de la era moderna, impresión en ocasiones artificial. 
Y en ese debate, entre inseguridad ciudadana y respeto a las garantías, se mueve el actual Derecho penal. Lo peor que nos puede pasar es que bajo el fundamento de más seguridad nos volvamos más inseguros, siendo ya no el temor al delincuente, sino viendo en el sistema penal la amenaza.

Lo cierto es que se camina por la alborada del tercer milenio y lejos de la tranquilidad deseada vivimos en una sociedad de riesgos. Algunos propios de la modernidad, otros, similares a los del pasado ya lejano. Como bien afirma Silva Sánchez (2001), no fueron los modelos de Estado de hace trescientos años los que expandieron el Derecho penal; sino que la industrialización fue el factor determinante de la aparición de aquellos riesgos que "justifican" la expansión. El penalista español afirma que el Derecho penal debe cumplir el fin de reducción de la violencia social, y ha de asumir también, en su configuración moderna, el fin de reducir la propia violencia punitiva del Estado. Esta reducción tiene lugar por dos maneras: sobre la base del principio utilitarista de la intervención mínima y sobre la base de los principios garantísticos individuales.

\section{Beccaria como precursor del derecho penal mínimo}

Algunas de las claves para entender el presente se encuentran en el pasado. César Beccaria y su obra cumbre De los Delitos y las Penas, publicada en 1764, puede servirnos de guía, a manera de hilo de Ariadna, para encontrar el camino de salida. La obra de Beccaria ha perdurado en el tiempo entre otras razones, porque sienta las bases para un sistema penal occidental, que en su época niega la tortura, las penas corporales, la sanción de muerte. Se cuestiona los fines mismos del Derecho penal, incluyendo la naturaleza y origen del derecho a castigar del soberano, hoy en manos del Estado.

Con solo 22 años, Bonesana sufre prisión, solicitada por su padre el Marqués de Beccaria, quien se oponía a la relación de su hijo con Teresa de Blasco. Es allí, en la dura cárcel del lejano 1760 donde sufre en carne propia los rigores y tormentos de la prisión. El sistema penitenciario propio del Derecho canónico de la época sin dudas siembra en el joven juicios contrarios al mismo. Por lo tanto, su filosofía relacionada con la pena y el delito está marcada por vivencias propias.

En palabras del propio Marqués expresadas al abate Morellet:

He oído el ruido de las cadenas que sacuden la superstición y el fanatismo, ahogando los gemidos de la verdad. La contemplación de ese espectáculo espantoso me 
determinó, a veces, a envolver la luz con nubes. He querido defender a la Humanidad sin hacerme su mártir. (Beccaria, 1993, p. 22)

Su obra constituye un punto de inflexión entre dos sistemas de enjuiciamiento. Uno totalitario, absoluto, expansivo, que prevalecía en la Europa fragmentada del Medioevo, que ya había observado la Revolución inglesa un siglo antes, por los inicios de 1642 y a solo dos décadas de la Revolución Francesa de 1789. Es una Europa donde el capitalismo va abriéndose paso y enterrando de manera lenta pero inexorable al sistema feudal. El otro sistema propio de la Ilustración va sustituyendo al oscurantismo que durante siglos, y de la mano de la iglesia católica se impuso como doctrina oficial de los estados.

En el campo del derecho se abre paso la concepción del derecho natural, anterior y superior al derecho positivo, del cual emanaban todas las demás manifestaciones del derecho. En el campo del Derecho Procesal, la humanidad comenzaba a salir del sistema inquisitivo y se adentraba en lo que posteriormente se ha conocido como el sistema mixto de enjuiciar. Por la época en que se publica la obra de Beccaria, los jueces del Tribunal de la Inquisición cerraban sus ojos al aforismo latino de Justiniano contenido en el Digesto del 533 d. C. y que rezaba "satius enim esse impunitum relinqui facinus nocetis quam innocentem damnari".

El humanismo y la proporcionalidad entre la pena y el delito cometido son referentes permanentes en la obra del italiano. "Otro principio sirve admirablemente para estrechar más y más la importante conexión entre el delito y la pena; éste es que sea ella conforme cuanto se pueda a la naturaleza del mismo delito" (Beccaria, 1993, p. 25). Al valorar el Marqués Beccaria los fines de la pena se muestra crítico contra los tormentos infligidos por el sistema penal de la época. No es cosa de cuentos, basta leer los tormentos ocasionados a un acusado ${ }^{2}$, que aparecen en la

\footnotetext{
${ }^{1}$ Es mejor dejar libre a un culpable que castigar a un inocente.

${ }^{2}$ Una buena referencia está en Foucault (2002), y la descripción que hace de la sentencia de Damiens, quien fue condenado, el 2 de marzo de 1757, a "pública retractación ante la puerta principal de la Iglesia de París", adonde debía ser "llevado y conducido en una carreta, desnudo, en camisa, con un hacha de cera encendida de dos libras de peso en la mano"; después, "en dicha carreta, a la plaza de Grève, y sobre un cadalso que allí habrá sido levantado [deberán serle] atenaceadas las tetillas, brazos, muslos y pantorrillas, y su mano derecha, asido en ésta el cuchillo con que cometió dicho parricidio,1 quemada con fuego de azufre, y sobre las partes atenaceadas se le verterá plomo derretido, aceite hirviendo, pez resina ardiente, cera y azufre fundidos juntamente, y a continuación, su cuerpo estirado y desmembrado por cuatro caballos y sus miembros y tronco consumidos en el fuego, reducidos a cenizas y sus cenizas arrojadas al viento". "Finalmente, se le descuartizó, refiere la Gazette d'Amsterdam. Esta última operación
} 
publicación periódica de Ámsterdam siete años antes de la publicación de su libro, y que seguramente presenció mientras estuvo en prisión.

La obra de Beccaria ha sido considerada por Antón (1964), como el "evangelio de los reformadores". La concepción retribucionista de considerar a la pena como un mal, que habría de ocasionársele a quien había producido otro mal es superada por Beccaria. Al respecto plantea:

Es mejor evitar los delitos que castigarlos. He aquí el fin principal de toda buena legislación, que es el arte de conducir los hombres al punto mayor de felicidad o al menor de infelicidad posible, para hablar según todos los cálculos de bienes y males de la vida [...] El temor de las leyes es saludable. (Beccaria, 1993, p. 20 )

Desde Beccaria nos ha llegado -y aún existe- el criterio según el cual la sanción no puede pretender la restauración del orden jurídico. El delito es en primer lugar (aquí se manifiesta su organicidad con la teoría del contrato social) un daño a la sociedad, afecta a los individuos que han acordado ciertas reglas para una convivencia de personas y derechos. El delincuente representa un peligro para la sociedad.

El derecho penal mínimo como ideal de justicia tiene sus antecedentes en el pensamiento liberal del siglo XVIII y siguientes. En Beccaria encontramos la primera expresión de lo que hoy llamamos principio de mínima intervención del Derecho penal (Asua, 1990).

Posteriormente, se producen varias reformas penales en la segunda mitad del siglo XX, fundamentalmente en las décadas del setenta y ochenta. Después este proceso de reforma penal fue truncado a finales de siglo y hoy está en franco retroceso en los inicios del XXI.

Una de las primeras lecciones que recibimos en las aulas, apuntan al necesario carácter de última ratio que tiene el Derecho Penal. Varias son las razones; entre ellas los elevados costes para la sociedad por su aplicación y su necesario carácter subsidiario. Es necesaria la mínima intervención. Sin embargo, todo apunta hacia la expansión desenfrenada del alcance de los sistemas penales. Una de las claves constituye esta denominada ya, sociedad de riesgo, donde surgen nuevos peligros medioambientales, industriales, tecnológicos que conllevan la incorporación de una

fue muy larga, porque los caballos que se utilizaban no estaban acostumbrados a tirar; de suerte que en lugar de cuatro, hubo que poner seis, y no bastando aún esto, fue forzoso para desmembrar los muslos del desdichado, cortarle los nervios y romperle a hachazos las coyunturas [...]”. 
gama de nuevos bienes jurídicos de naturaleza colectiva. ¿Cómo frenar el proceso inflacionario de las normas penales? Imponiendo límites es la respuesta segura de la dogmática penal contemporánea. Sin embargo, resulta admitir la posibilidad de que el poder instituido se autolimite a sí mismo.

Hablar de derecho penal mínimo es llevar a la esfera de aplicación del Derecho penal el mínimo de conductas transgresoras. En la evolución del ius puniendi podemos apreciar que no ha sido lineal, pacífica y que por demás no apunta a límites concretos. Hay quienes afirman que el Derecho penal camina hacia su propia tumba y será reemplazado por un nuevo derecho correccional construido sobre bases positivistas (Dorado, 1995).

Autores de nuestra región como Zaffaroni (1998) expresan que las leyes penales son insuficientes para frenar el crimen, y más ante la globalización que experimenta la humanidad, fomentándose desde el Derecho penal, la criminalización de los entes menos favorecidos por el mercado.

Algunos de los principios del Derecho penal responden a concepciones de última ratio, entre estos encontramos el carácter fragmentario y el carácter subsidiario del mismo. Según el principio de subsidiariedad, el Derecho penal ha de ser la última ratio, el último recurso a utilizar a falta de otros menos lesivos. El llamado carácter fragmentario del Derecho penal constituye una exigencia relacionada con la anterior. Ambos postulados integran el llamado principio de intervención mínima. El Derecho penal siguiendo esta línea, solo debe proteger bienes jurídicos, sin embargo no significa que todo bien jurídico haya de ser protegido penalmente, ni tampoco que todo ataque a los bienes jurídicos penalmente tutelados deba determinar la intervención del Derecho penal.

Cuando se afirma que el Derecho penal tiene un carácter fragmentario, término utilizado inicialmente por Binding, se quiere indicar que éste solo debe intervenir frente a aquellos comportamientos que atenten contra las reglas mínimas de la convivencia social (esto es, a los bienes o valores jurídicos fundamentales de la persona y de la sociedad), siempre y cuando, además, dichos comportamientos se lleven a cabo de una forma especialmente graves. Cuando se dice que el Derecho penal es la última ratio del ordenamiento jurídico se quiere indicar que la intervención penal (prevención general del delito a través de la pena) solo es lícita en aquellos supuestos en los que el Estado, previamente, ha agotado todas las posibilidades no penales (culturales, educacionales, asistenciales, de política general) y pese a todo, de ahí su naturaleza subsidiaria, persisten los conflictos agudos de desviación. Se 
impone la presencia de dos elementos para que el Derecho penal actúe: que el bien jurídico posea importancia y que la lesión a este sea grave.

Un Derecho penal de última ratio no solo implica determinar cuáles han de ser los bienes jurídicos a tutelar, está imbuido en la idea de una respuesta penal alternativa a la pena privativa de libertad. En fin, la formalización legal de la pena constituye un presupuesto esencial también para su minimización conforme al criterio, utilitarista y humanitario, expresado por la tesis nulla poena sine necessitate. $Y$ esa pena no tendrá por finalidad el castigo del reo. El fin último, como manifiesta Beccaria, es la prevención de nuevos delitos.

Algunas de estas tesis, ofrecen sustento a tendencias modernas como la del llamado Derecho penal del enemigo. Como corriente de pensamiento supone una perversión del necesario carácter de última ratio de las normas penales. Implica un Derecho penal de dos velocidades; un sistema penal garantista para los ciudadanos y otro perverso para los declarados enemigos. El enemigo para Jakobs constituye la antítesis del ciudadano. Recordemos que en la actualidad este autor contrapone la vigencia de la norma como función del Derecho penal a la concepción predominante (Roxin, 1997) enfocada en la protección de bienes jurídicos, y la prevención como fin de la pena.

Este autor sintetiza en tres los elementos que caracterizan el susodicho Derecho penal del enemigo según la concepción que defiende y que debe ser señalada como la más caracterizada: a) supone un amplio adelantamiento de la punibilidad; b) las penas previstas son desproporcionadamente altas, por lo que el elemento anterior no es tenido en cuenta para reducir en correspondencia la pena amenazada; c) determinadas garantías procesales son relativizadas o incluso suprimidas (Cancio, 2003).

\section{3. ¿Por qué castigar? La lesividad como límite al ius puniendi del Estado}

En la actualidad, la concepción predominante sobre el llamado ius puniendi del Estado es considerarlo como un derecho a castigar, reconocido al Estado por la propia constitución. El derecho a castigar, según tales criterios tiene carácter constitucional. "[...] el ius puniendi ha de ejercerse en la sola medida exigida por la protección de la sociedad, es el llamado "carácter fragmentario" del Derecho penal. Significa que el Derecho penal no sanciona todas las conductas lesivas de bienes jurídicos, sino solo las modalidades de ataque más peligrosas para ellos” (Mir Puig, 1976, p. 30). 
En la obra de Beccaria, su sistema filosófico y jurídico se basa en la concepción del contrato social. El propio dogma nullum crimen, nulla poena sine lege constituye en sí mismo una garantía que el italiano reconoce de manera implícita al afirmar que "[...] la primera consecuencia de estos principios es que solo las leyes pueden decretar las penas de los delitos; y esta autoridad debe residir únicamente en el legislador, que representa toda la sociedad unida por el contrato social" (Beccaria, 1993, p. 28).

Esta concepción del contrato social, dentro del ius naturalismo como corriente ideológica y jurídica de finales del siglo XVIII ha sido retomada una y otra vez para encontrarle justificación, desde otras posiciones, a las relaciones entre Estado-sociedad-individuo.

En la actualidad es el Estado quien tiene la potestad del ius puniendi. Los defendidos límites normativos (Silva Sánchez, 1999; Schonfeld, 2014) del Derecho penal sobre la base de criterios funcionalistas (correcta interpretación del ámbito de protección de la norma penal) o garantistas (adecuación correcta de los medios formales de aplicación del poder punitivo con la constitución) resultan -a nuestro modo de ver- inexistentes, si se parte de que el propio poder instituido sería el que limitaría su poder punitivo.

En nuestro criterio, el ius puniendi más que derecho subjetivo del estado (Soler, 1992; Medina, 2001) o potestad del Estado para castigar (Nuñez, 1999) constituye un límite en sí mismo, límite formal, pues estaríamos hablando del Estado auto limitándose en sus funciones. Constituye una función del Estado ${ }^{3}$, un deber ${ }^{4}$, una obligación (Obligatio ad faciendum) generada por las propias funciones del Estado.

${ }^{3}$ Autores como Carbonell (1998), plantean que "ha de considerarse indiscutible que no se trata del ejercicio de ningún derecho subjetivo, sino de las funciones que corresponden al Estado en virtud del pacto social traducido en la Constitución. El poder de crear normas penales no tiene diferentes características que el de legislar en materia de cultura, obras públicas o educación, si bien, a diferencia de esas materias, y como ya sabemos, el Derecho penal supone recortes a la libertad general con el fin de tutelar las libertades de los ciudadanos".

${ }^{4}$ La concepción tradicional del ius puniendi como derecho a castigar del Estado resulta a nuestro modo de ver, incorrecta. Desde una concepción liberal ciertamente podría defenderse la categoría derecho, lo cual refuerza criterios como la existencia de una relación cuasi-contractual entre Estado e individuo. ¿Por qué nace en el individuo que comete un delito la obligación de sufrir una pena? Desde una posición marxista, que niega llevar al plano contractual las relaciones Estado- sociedad civil, más que derecho debe considerarse potestad y deber. Potestad porque solo el Estado está legitimado a través de sus órganos jurisdiccionales para dictar las leyes y perseguir los delitos. Constituye a la vez un deber que se sustenta en las funciones del Estado. E1 Estado tiene el deber de delimitar las conductas constitutivas de delito y la obligación -no derecho- a perseguirlas y sancionarlas. La razón de ser del Estado es precisamente garantizar la coexistencia, la estabilidad de la sociedad, tiene encomendado 
En el ámbito penal, Beccaria puede ser considerado uno de los precursores de la teoría de la dañosidad social. Para una teoría marxista del delito -que podemos considerar en permanente construcción- resulta dogmáticamente más garantista y eficaz hablar de la dañosidad social como uno de los rasgos del delito que los criterios de la peligrosidad social heredados del socialismo del este europeo con claras influencias del positivismo italiano de inicios del siglo XX. Con la dañosidad social podríamos hablar ciertamente de lesividad (nullum crime sine inuria) como principio del Derecho penal, donde solo se justifica la aplicación de la pena cuando se han lesionado o puesto en peligro bienes jurídicos fundamentales.

La lesividad u ofensividad expresada en el dogma nullum crimen sine iniuria constituye un indicador de la antijuricidad de la conducta. La lesividad como principio surge ya en Aristóteles y Epicuro y que es denominador común a toda la cultura penal ilustrada de Hobbes, Pufendorf y Locke a Beccaria, Hommel, Bentham, Pagano y Romagnosi, quienes ven en el daño causado a terceros las razones, los criterios y la medida de las prohibiciones y de las penas (Muñoz Conde, 1984).

No basta que se hayan afectado determinados bienes, es necesario que estos bienes tengan naturaleza jurídica. Siendo así, el principio de lesividad constituye en sí mismo una barrera -digamos interna- ante la potestad legislativa del Estado. La ofensividad depende que se lleve o no al plano del derecho positivo determinada conducta, representa por tanto, el principio de legalidad de los delitos y las penas el primer presupuesto para considerar la existencia de un bien jurídico. La contradicción del hecho con la norma penal prohibitiva o permisiva -el comportamiento definido por el deber ser versus el ser- que integra lo penalmente típico, conduce a la verificación de que se ha cometido un delito, se ha materializado una conducta definida como delito (nullum crimen sine lege nullum poenae sine crimen) implica además que se ha atacado un bien jurídico.

Entre las complejidades a las que dogmáticamente se enfrenta este principio está la justificación de tutela de bienes jurídicos colectivos. La defensa de lo social frente a los valores tradicionales que constituyeron el sustento de la teoría del bien jurídico, ha provocado un sobredimensionamiento en el mismo, llegando a constituirse en un fetichismo jurídico. Constituye una razón esgrimida ante cada avance expansivo de las normas penales. Se le usa como llave mágica que justifica

ese rol. Para poder cumplirlo de forma satisfactoria deberá prohibir y penar determinadas conductas, a fin de poder proteger de manera efectiva los bienes jurídicos políticamente importantes para la clase dominante (Fontán, 1998). 
la punición de nuevas y nuevas conductas. Para Zaffaroni (1998), el principio de lesividad implica que ningún derecho puede legitimar una intervención punitiva cuando no media por lo menos un conflicto jurídico, entendido como la afectación de un bien jurídico total o parcialmente ajeno, individual o colectivo.

La exigencia de que se lesione o ponga en peligro un bien jurídico penalmente tutelado constituye una garantía procedimental para el individuo frente al poder sancionador del Estado, estando estrechamente ligado al clásico principio de legalidad. En materia de delincuencia económica se puede afirmar que ciertamente se afectan con este tipo de conductas, diversos bienes jurídicos. En los procesos contractuales donde se han producido serias afectaciones patrimoniales se puede afirmar que opera la lesividad, pues hay un bien jurídico penal afectado. No obstante cabría hacerse la pregunta si ¿este bien jurídico se puede proteger desde otras ramas del derecho menos violentas? En los inicios decíamos que el Derecho penal protege bienes jurídicos de manera subsidiaria, a manera de segunda barrera de contención.

La lesividad vista desde otra óptica puede identificarse con el carácter antijurídico de la conducta, la antijuricidad como rasgo del delito implica que dogmáticamente la norma existe porque protege bienes vitales a la sociedad y el individuo, más allá de clasificaciones teóricas sobre bienes individuales y colectivos. Resulta antijurídica y reprochable la conducta a partir de que ataca no ya normas, sino bienes. El legislador configuró determinado comportamiento como delito no para garantizar la vigencia de una norma jurídica, lo hace para a través de esa norma proteger intereses vitales a la sociedad, y solo cuando el ataque esté configurado como muy grave. En este sentido opera el principio de lesividad.

Concretar la ofensividad requiere en primer lugar que la conducta encuentre correspondencia en el tipo penal, y supone una valoración especial en los delitos de peligro abstracto o presunto. ¿En qué medida la conducta ha puesto en peligro el bien jurídico tutelado? La existencia del peligro se constituye en la posibilidad del resultado de daño en su futuro y probable desarrollo. No constituye una posibilidad segura, ya que a pesar de la situación de peligro, el resultado dañoso podrá o no producirse. Constituyen delitos de mera actividad.

Otra cuestión se planeta cuando la conducta es casi irrelevante desde el punto de vista penal, lo que podríamos llamar insignificante o exigua. Los llamados delitos "bagatelarios I reati bagattellar" representan una negación de la lesividad de la conducta, en este caso o no se está protegiendo un bien jurídico o este no es relevante a los efectos penales. Los delitos bagatelarios, por otra parte, suponen la 
negación del carácter de última ratio del Derecho penal, específicamente su carácter subsidiario. También depende de la dañosidad social de la conducta lesiva, con la que no se corresponde necesariamente la desvaloración del comportamiento lesivo para los bienes (Jakobs, 1997). No podemos seguir utilizando -amén de lo expresado por la legislación nacional- el criterio ya superado de la peligrosidad social. El tránsito ha de ser hacia la dañosidad social, ya enunciado por Beccaria hace dos siglos y medio.

\section{La expansión de las normas penales. Valoraciones en el ámbito económico}

La expansión de las normas penales potenciada por la globalización económica y que encuentra asidero en una sociedad enfrentada a nuevos y viejos riesgos latentes conduce inexorablemente al redimensionamiento del alcance, pero también eficacia del Derecho penal contemporáneo. Cuando los autores modernos (Schonfel, 2014) analizan el fenómeno de la expansión generalmente se aborda el fenómeno desde una expansión -que en nuestro criterio catalogamos- hacia adelante. Aumentan los tipos penales, aparecen nuevas figuras agravadas, se incrementan los delitos de peligro, se protegen bienes jurídicos colectivos, etc. Sin embargo, consideramos pertinente apuntar que esta expansión no solo es hacia delante, también ocurre de una manera más disimulada hacia atrás, hacia lo que denominamos formas de anticipación de la tutela penal.

Dentro de las manifestaciones podemos encontrar la configuración de tipos penales que desde la teoría del iter críminis clásicas tentativas son configurados como delitos consumados, actos preparatorios llevados a la categoría de figuras delictivas, conductas reguladas por el Derecho administrativo pasan a formar parte del catálogo de los delitos, entre otros.

Con la creación de los delitos de peligro se busca la anticipación de la reacción penal al delito, y con ello se penalizan conductas que no llegan a ser concretas, pero que pueden dañar intereses "relevantes" de la sociedad. No se puede hablar estrictamente de tutela a bienes jurídicos individuales y mucho menos determinados, pero sí de intereses vulnerables de la identidad de la sociedad (de esta forma los denominan Jakobs y Cancio, Derecho penal del enemigo) (Cancio, 2003).

${ }^{5}$ Otros autores se han referido en el mismo sentido: Escobar (2009), Mendoza (s.f.), Silva Sánchez (1999), Serrano (2005), y Morillas (2005). 
El tránsito de un Derecho penal protector de bienes jurídicos individuales, clásicos, hacia nuevos objetos de tutela penal puede ser asumido como una manifestación del proceso de expansión que se ha producido en las últimas décadas. El medio ambiente, la seguridad colectiva, la economía nacional o el buen funcionamiento de la administración y jurisdicción no aparecían en los primeros códigos de derecho canónico del medioevo. El nuevo escenario en materia económica hacia donde confluyen las normas penales está presente en momentos donde la globalización convierte al planeta en la aldea global.

Los cambios que se han producido en el entorno económico mundial a partir de la globalización económica y el propio desarrollo de la sociedad imponen transformaciones al sistema de relaciones sociales y jurídicas existentes. Se justifican las normas penales que crean nuevos delitos cuando estos surgen al adaptarse la sociedad a estos nuevos escenarios. Es entendible entonces que aparezcan nuevos delitos, pero también que desaparezcan otros.

Hay un grupo de causas objetivas que han incidido en esta expansión. Ya mencionábamos la globalización económica, y la permanente sensación de peligro de la sociedad moderna, en buena medida formada por los medios hegemónicos de comunicación. Como diría Silva Sánchez:

Los medios, que son el instrumento de la indignación y de la cólera públicas, pueden acelerar la invasión de la democracia por la emoción, propagar una sensación de miedo y de victimización e introducir de nuevo en el corazón del individualismo moderno el mecanismo del chivo expiatorio que se creía reservado para tiempos revueltos $[\ldots]$ Los asesinatos de niños se convierten en acontecimientos nacionales para una opinión pública fascinada por la muerte y la transgresión. Su exasperación por los medios acabará por hacer creer al ciudadano no avisado que este tipo de crímenes es frecuente, lo que no es el caso. (1999, p. 33)

Otro de los elementos apunta al desarrollo tecnológico y su utilización por la delincuencia inter y trasnacional, que ha llevado a los Estados a la búsqueda y aplicación de nuevas formas y maneras de lucha contra el delito, que en algunos casos y de manera lamentable, afectan garantías y principios básicos de la dignidad humana.

$\mathrm{El}$ intercambio económico mundial genera mayores volúmenes de comercio. Ante un mayor número de operaciones aduaneras, financieras y contables mayores posibilidades de ilícitos se manifiestan. Como afirmaron hace ya algunas décadas 
López y Arrojo (1976) “[...] el delito ya no es la entidad científica elaborada por destacados criminólogos sino un fenómeno sociopolítico en proceso de rápida expansión, estrechamente relacionado con la estructura global de la sociedad, que no puede identificarse con la imagen de un establishment determinado, sea capitalista o socialista" (p. 352).

Desde otra perspectiva se hace uso del Derecho Penal -a nuestro modo de vercomo herramienta eficaz en la detección y combate rápido y eficiente pues logra un efecto determinado sobre las formas de actuar fraudulentas y extremadamente lesivas a la economía de un país. Lo que no queda del todo asegurado es la eficacia de esas mismas normas penales, si se logran los fines a los que se aspira.

La expansión es metafóricamente hablando, un avance veloz del Derecho penal por las autopistas de la economía, no ya tras el delincuente tradicional mal vestido, mal educado y producto de barrios marginales, sino una marcha a toda velocidad, en ocasiones sin clara noción del final del viaje, ante la marcha rezagada de un Derecho administrativo extenso, enrevesado y vulnerable que no es capaz de prevenir y sancionar eficazmente a un corporativo elegante y extremadamente capacitado. En vez de cuchillos y armas de fuego hablamos de contratos, negociaciones, operaciones millonarias, rostros felices ante cámaras de televisión que auguran un desarrollo económico impetuoso. Al cabo de los meses o años es que aparecen las defraudaciones, el daño al país y a su gente. Casi siempre el corporativo elegante disfruta en su país de los millones robados, mientras se procesa penalmente a funcionarios de mediano rango que tuvieron la desdicha de aportar sus rostros como acusados.

Dentro de este auge ha venido surgiendo una criminalidad económica, cuyos perfiles delictivos son cada vez más sofisticados y complejos, asunto que admite necesariamente incluir métodos efectivos de enfrentamiento, investigación, persecución y sanción a la delincuencia económica, coherente y racionalmente en atención a la agresividad, nocividad y afectaciones que se producen por la ocurrencia de estas conductas transgresoras de la ley penal.

La función de garantía del bien jurídico puede constituir la primera barrera en el sentido de descongestionar las leyes penales y dotarlas del necesario carácter subsidiario del Derecho penal. La llamada función reductora del Derecho penal implicaría que éste es tremendamente ineficaz cuando se le tiene por la herramienta principal para el desarrollo económico de un país. Los mecanismos económicos para la solución de conflictos, tanto los tradicionales como los alternativos siempre serán menos onerosos que la solución penal. 
En los procesos asociados a formas de contratación económica se manifiestan delitos que destacan por el carácter pluriofensivo de los mismos. Varios son los bienes jurídicos afectados por las conductas de los agentes económicos comisores de delitos. En los procesos contractuales, aun en su etapa de negociación, ciertamente pueden vulnerarse bienes jurídicos tutelados por las normas penales. El problema no radica en penar todas estas conductas. La génesis radica en el análisis exegético que se realice de lo tutelado por los tipos penales. Y -en primerísimo lugar- delimitar conscientemente que conductas han de sancionarse.

En los delitos económicos donde existe un sujeto definitivamente diferente al delincuente tradicional, podrían realizarse las mismas preguntas que Zaffaroni formula en su ponencia sobre la lógica del carnicero y el Derecho penal. ¿Qué fines se logran, además de la represión del delito, cuando se envía a prisión por largos años a un individuo que en la negociación de un contrato ha afectado los intereses económicos del país o el buen funcionamiento de la administración?

¿Se protegen realmente bienes jurídicos al configurar tipos penales que sancionan las conductas impropias de los funcionarios en los procesos de negociación de contratos? ¿Estas normas realmente motivan al resto de los individuos al respeto de la Ley? En pocas ocasiones se logra la recuperación de los activos defraudados. Consideramos que el fin preventivo pocas veces se logra, este tipo de delincuencia crece y se expande ante la ineficiencia del Derecho administrativo. No es el temor a la sanción penal lo que evita la comisión de estos delitos, sino la existencia real y eficiente de mecanismos de control en las propias entidades.

Que el Derecho penal no logre sus fines (efectiva protección de bienes jurídicos y motivación de los ciudadanos hacia el respeto al orden social y jurídico) resulta preocupante, pero más peligroso aún consiste en una expansión desenfrenada hacia más Derecho penal.

Más allá de la cuestión relativa a la capacidad de una puesta en peligro abstracto de bienes jurídicos supraindividuales para constituir un injusto que fundamente culpabilidad, en el Derecho penal económico se presenta un problema de culpabilidad más específico aún. Pues el reproche ético-jurídico de la conducta no solo tiene por objeto el fracaso del autor en un rol social específico, sino que lo afecta en todos los espacios de ejercicio de sus roles y, con ello, en todos sus roles. De esta forma, la pena apunta al ser humano como persona, es decir, como aquel sujeto que es libre y responsable en la vida social. 
Dentro de este panorama de necesidad de prevención masiva y prevención de riesgos, se desarrolla el Derecho penal económico. Probablemente, de ahí proviene la penuria de crear tipos penales como los de peligro, estudiados hasta el momento. Estos delitos de peligro abstracto, que a diferencia de los tipos penales de lesión, no hay daño a un objeto concreto, solo hay un peligro en la producción de la lesión, son un claro ejemplo de lo que sucede en la materia.

Esta necesidad de prevenir riesgos futuros acaece en el derecho penal moderno, olvidando las funciones que tenían las garantías y principios en el derecho penal clásico. Y aunque la doctrina lo advierta, el legislador es poco renuente a aceptar una reducción del Derecho penal, posiblemente por las presiones sociales y de prensa a las que son sometidos los legisladores. En fin, después de dos siglos y medio, con otras características y en otro tiempo, el sobredimensionamiento del Derecho penal necesita una revisión crítica. Si Beccaria enfrentó en su época el absolutismo político y jurídico predominante en los Estados europeos, lo que se ha producido en las dos últimas décadas ha significado un retroceso respecto a lo logrado en las décadas del setenta y ochenta del siglo pasado. La obra del Marqués perduró en el tiempo al establecer bases sólidas para la construcción de un Derecho penal garantista y humano. Hoy puede servir para encontrar nuevamente el rumbo, para lograr que sea un derecho de última ratio, ante el actual panorama, que solo apunte hacia la expansión del sentido y alcance de las normas penales.

\section{Conclusiones}

Anterior a Beccaria venía produciéndose en el campo de la filosofía y el derecho una evolución hacia el llamado Derecho natural. Empiezan a definirse de manera nítida las bases de varios de los principios y garantías político-procesales que hoy conforman el Derecho penal contemporáneo. Lo anterior, unido al entorno familiar de Beccaria conforma una base filosófica y jurídica que se sintetiza en el libro De los Delitos y las Penas, una obra de amplia difusión y calado en las generaciones de juristas y filósofos penales de la época y del presente. Este libro constituye una piedra angular del pensamiento penal contemporáneo. Cuestiones tales como la facultad de sancionar, la legitimidad y fines de las penas, los excesos del poder absoluto de los monarcas y la imperiosa necesidad de actualizar las leyes vigentes de la época, establecen las bases para un programa de reducción del Derecho penal en su conjunto. 
Las ideas de Beccaria han perdurado en el tiempo a partir de representar las aspiraciones de una época, relacionadas con limitar el poder punitivo del Estado frente a los excesos de este. Beccaria se inscribe en el movimiento iluminista de finales del siglo XVIII que fundamenta desde postulados filosóficos y jurídicos la necesidad de un derecho más humano y garantista. Constituyen una base sólida para la concreción, desde lo legislativo, de un Derecho penal mínimo, respetuoso del carácter subsidiario y fragmentario que deben tener las normas penales.

En las décadas del setenta y el ochenta del siglo XX se produce un movimiento reformador del Derecho penal en sus principales categorías e instituciones, propiciando la fundamentación y concreción de garantías y principios. En este escenario se retoman varias de las ideas de Beccaria referidas al carácter mínimo del Derecho penal y la necesaria humanidad de las penas.

En la década del noventa del pasado siglo y principios del presente empieza a avanzar con mayor rapidez una expansión del Derecho penal en su conjunto. Entre las causas de este sobredimensionamiento pueden citarse el auge del terrorismo, la aparición de nuevos riesgos para la sociedad vinculados a la globalización económica, el medio ambiente, la violencia e inseguridad ciudadana, entre otros. Algunas de sus características son la incorporación de nuevos bienes jurídicos, fundamentalmente de naturaleza colectiva, la penalización de conductas anteriormente reguladas por el Derecho administrativo y la anticipación de la tutela penal por solo citar algunos.

El proceso expansivo en materia penal se aleja del necesario carácter mínimo del Derecho Penal fundamentado ya por Beccaria hace dos siglos y medio. Las ideas de este autor pueden servir de punto de partida para el necesario debate y revisión de la legislación penal contemporánea, a fin de dotarla del carácter humano y garantista que se fue construyendo durante más de dos siglos. Esta expansión representa un reto para la dogmática penal actual, y para salir airosos de dicho reto pueden tomarse de paradigmas algunas de las tesis planteadas en el libro De los Delitos y las Penas.

\section{Referencias}

Antón, J. (1964). Los fines de la pena según los penalistas de la ilustración (p. 415). En revista de estudios penitenciarios, no. 66.

Asúa, A. (1990). Reivindicación o superación del programa beccaria. En Asúa Batarrita, Adela, ed., el pensamiento penal de beccaria: su actualidad, bilbao, ed. Universidad de Deusto. 
Bacigalupo, E. (1996). Manual de derecho penal. Tercera reimpresión. Bogotá: Editorial Temis.

Beccaria, C. (1993). De los delitos y las penas. Buenos Aires: Editorial Heliasta s.r.l.

Cancio, M. (2003). ¿Derecho penal del enemigo? En Jakobs, Günther-Cancio Meliá, Manuel. Derecho penal del enemigo. Madrid.

Carbonell, J. (1996). Derecho penal: concepto y principios constitucionales. 2a ed, adaptada al código penal de 1995. Tirant lo Blanch.

Dorado, P. (1995). Del derecho penal represivo al preventivo, en: derecho protector de los criminales. Madrid.

Fontán, C. (1998). Derecho penal. Introducción y parte general. Buenos Aires: Abeledo-Perrot.

Foucault, M. (2002). Vigilar y castigar (p. 1). Recuperado de http://www.ivanillich.org.mx/ Foucault-Castigar.pdf

Hans-Joaquim, R. (1991). El fin del derecho penal del estado y las formas de imputación jurídicopenal. En el sistema moderno del derecho penal: cuestiones fundamentales. Estudios en honor de Claus Roxin en su 50 aniversario. Compilado por Bernd Schünemann, introducción, traducción y notas de Jesús-María Silva Sánchez. Madrid: Editorial Tecnos.

Jakobs, G. (1997). Derecho penal (parte general) .fundamentos y teoría de la imputación. Segunda edición corregida. Traducción de Joaquín Cuello Contreras y José Luis Serrano González de Murillo. Madrid, España: Editorial Marcial Pons.

López y Arrojo. (1976). El Derecho Penal Enemigo. Recuperado de http/www. biblio. juridicas.unam.mx

Medina, A. (2001). Losprincipios limitativos del iuspuniendi. su incidencia en la determinación de la pena y su consagración en las constituciones nacionales y en los instrumentos jurídicos adoptados por la comunidad internacional. Trabajo de investigación defendido en opción del título de master en derecho público, en el departamento de derecho penal de la facultad de derecho de la Universidad de Valencia, España.

Mir Puig, S. (1976). Introducción a las bases del derecho penal. Barcelona, España: ed. Bosch.

Nuñez, R. (1999) Manual del derecho penal parte general. Cuarta edición actualizada por Roberto E. Spinka y Félix González. Argentina: Editorial Córdoba.

Pedraz, E. (1989). Notas sobre publicidad y proceso. En poder judicial, no. XI especial, c.g.p.j. el poder judicial en el consejo de los poderes del estado y de la sociedad.

Quintero, G. (1976). Habla de "potestad punitiva” en represión penal y Estado de derecho. Barcelona.

Quirós, R. (1999). Manual de derecho penal. Tomo I. Varela, La Habana: Editorial Félix.

Roxin, C. (1997). Derechopenal. Parte general. Tomo I. Fundamentos. La estructura de la teoría del delito. Editorial Civitas. 
Schonfeld, L. (s.f) La expansión del derecho penal como politica demagógica y sus límites._Recuperado de http://www.alfonsozambrano.com/doctrina_penal/expansion_dpenal1.pdf

Serrano, M. (julio, 2005). La expansión del derecho penal en el ámbito de la delincuencia económica. La tutela penal de los mercados financieros. Revista de derecho de Valdivia, vol. XVIII $n^{\circ} 1$.

Soler, S. (1992). Derecho penal argentino. Buenos Aires: Tipográfica editora Argentina.

Zaffaroni, E. (1998). Tratado de derecho penal. Parte general .Tomo I. Buenos Aires, Argentina: Ediar.

Zaffaroni, E. (2007). Globalización y crimen organizado. El poder en la globalización. Recuperado de http://www.alfonsozambrano.com/doctrina_penal/globalizacion_crimen_organizado.pdf 